JHR

33,3

186

Received 21 July 2018

Revised 24 September 2018

Accepted 12 November 2018

\section{Effects of mindfulness-based health education practice on health behaviors and quality of life among hypertensive patients A quasi-experimental research}

\author{
Pantip Sangprasert, Srimuang Palangrit and Natima Tiyoa \\ Department of Community and Family Medicine, Faculty of Medicine, \\ Thammasat University, Pathum Thani, Thailand, and \\ Junya Pattaraarchachai \\ Chulabhorn International College of Medicine, Faculty of Medicine, \\ Thammasat University, Pathum Thani, Thailand
}

\begin{abstract}
Purpose - The purpose of this paper is to examine the effect of mindfulness practice on health behaviors and quality of life (QOL) among hypertensive patients.

Design/methodology/approach - A quasi-experimental research was designed by before, after and a follow-up phase (i.e. on the 0th, 6th and 12th weeks). Two primary health care units (PCU) were selected as control and experiment groups. Samples included patients 35-59 years old who had been diagnosed with stage I hypertension. Both groups received treatment according to standard hypertension guidelines. The experimental group was added as a drill for the purpose of a mindfulness-based health education (MBHE) practice that would emphasize behavior skills (in diet, exercise and mental function) and instill a feeling of adaptation to everyday life.

Findings - The total mean score of the prevention and promotional hypertension behaviors (PPHB), QOL, perceived in mindfulness (MF) and self-efficacy (SE) in the experiment group showed a significant statistical difference when compared to the control group in the 6th week in PPHB and SE $(p<0.001)$, QOL and MF $(p=0.001)$. Similar results were found in the 12th week in PPHB, QOL, SE $(p<0.001)$ and MF $(p=0.023)$, respectively.

Research limitations/implications - However, finished implementation in experiment group, during the follow-up phase on the 12th week, ten participants in the control group were excluded (Figure 1). It may be no active intervention or as usual in the control group. Thus, the authors controlled missing data using intention-to-treat analysis comparison and the data distribution was successfully tested by a normality plot before the use of statistical data. Based on the results of this study, the following recommendations can be made: patients should practice in mindfulness in lifestyle modification continued for intensive skill practice over the long term in order to promote sustainability in behavior and in QOL.

Practical implications - Mindfulness trainer should drill and faith in the value of mindfulness corporation owner with patients learning all of the times; and for health practitioner, it should add MBHE for patients. Social implications - Education institution should add mindfulness in educational programs all of graduates. Originality/value - The mindfulness practice-based health education training should be in counterpart with modern medicine in order to promote sound health behaviors and an improved QOL for stage I hypertensive patients and to forestall cardiovascular and blood-pressure diseases.
\end{abstract}

Keywords Quality of life, Health behaviour, Health education, Hypertension, Mindfulness practice Paper type Research paper

(c) Pantip Sangprasert, Srimuang Palangrit, Natima Tiyoa and Junya Pattaraarchachai. Published in Journal of Health Research. Published by Emerald Publishing Limited. This article is published under the Creative Commons Attribution (CC BY 4.0) licence. Anyone may reproduce, distribute, translate and create derivative works of this article (for both commercial and non-commercial purposes), subject to full attribution to the original publication and authors. The full terms of this licence may be seen at $\mathrm{http} / / /$ creativecommons.org/licences/by/4.0/legalcode

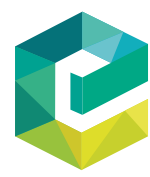

Journal of Health Research Vol. 33 No. 3,2019 pp. 186-196 Emerald Publishing Limited 2586-940X DOI 10.1108/JHR-07-2018-0059 


\section{Introduction}

In recent years, mindfulness-based health practices have been used to promote mental awareness. Conscious mental activity recognizes and accepts mentally perceived experiences according to Kabat-Zin[1]. In addition, spirituality offers a form of concentration that involves a relaxed and clear mind in conjunction with mental processes[2]. Mental activity of this sort, in turn, positively affects perceived self-efficacy (SE) in behaviors that are conducive toward the promotion of health and quality of life (QOL)[3-5]. These behaviors involve holistic physical, mental, emotional and social interactions with the individual's environment. Previous systematic review and meta-analysis research showed the positive results of mindfulness-based stress reduction and mindfulness-based cognitive therapy in the physical and mental well-being of patients suffering from chronic vascular disease[6]. However, the use of these interventions was rare in the evaluation of the health behavior outcomes in vascular disease even though the modifications they incurred had the potential to reduce complications of the disease. The Center for Disease Control[7] reported complications of hypertension as causes of mortality rates, such as cardiovascular, cerebrovascular and nephropathy-related disease.

In early 2017, we conducted literature research of PubMed, Scopus, CINAHL, Web of Science, PsycINFO and Mosby's Nursing Consult[8]. Literature from the above-named sources reviewed principle groups of strategic mindfulness in vascular disease. The results showed that self-reflective or group work induced intention, attention and attitude encouraged awareness, acceptance and self-regulation toward an individual's perception of body and mind symptoms. This broadened thinking added a new experience derived from deep listening in group procession opportunities. Specifically, it provided a means for the promotion and perceived ability of a positive and clear mind to observe cognitive memory as well as emotion. In addition, stress reduction and compassion increased SE of behavioral promotion and QOL[2, 3].

Previously, although patients received health education from health care centers and other information about behavior modification methods, health behavior-related education did not succeed in increasing awareness and did not help to alleviate mortality rates from the complications of hypertension. Indeed, this points to a specific research knowledge gap that necessitates a solution. Previous studies researched the benefits of mindfulness in health education as well as the health promotion of adult and community health education tools, trends and methodologies[9]. The positive effects perceived in SE in health promotion behaviors showed that the concept of Pender's model[3] in the social learning theory could be integrated to be conducive toward health education in mindfulness[3-5]. Hence, these studies can be defined as awareness acceptance and self-regulation of one's intention, attention and attitude toward flexibility and self-management of behaviors by focusing on new direct experiences.

The purpose of the current study was to examine the effectiveness of mindfulness-based health education (MBHE) on stage I hypertensive patients. The primary outcome was the effect of prevention and promotional hypertension behaviors (PPHB), while the secondary outcome was related to the QOL and perception of mindfulness and SE. Thus, we hypothesized that after implementing an MBHE program, behavioral changes could be promoted amongst patients that would, in turn, lead to an improvement in their QOL.

\section{Materials}

Study design and research settings

A quasi-experimental design was used, incorporating a three-time measurement specifically planned for this study. The study area was from two primary care units (PCUs) located in two districts of Pathum Thani province, Thailand. A period of 12 weeks was set as the duration of this study (July 2017 to September 2017). 
JHR

33,3

188

All participants were initially screened from each PCU by computerized recruitment methods based on inclusion criteria and a matched group of demographic data allocation. All 52 participants complied with the following inclusion criteria: that they had to be between the ages of 35 and 59 years; had to be diagnosed with stage I hypertension[10] and on an antihypertensive drug; had no underlining complications of hypertension[11]; and had an understanding of the Thai language. Participants who had a limited learning process, organic brain syndrome or a history of psychiatric problems were excluded from this study in order to control the confounding effects of the mindfulness learning process $[12,13]$.

The sample size was predetermined based on power analysis using G*Power[14] statistics with the effect size set at 0.4 , statistical power at 0.80 and $p$-value at 0.05 obtaining a sample of at least 23 participants per group. Approximately, 10 percent of participants were added in case of dropouts in order to obtain the final sample of 26 participants per group as shown in Figure 1.

\section{Outcome measures}

The demographic data questionnaires of hypertensive patients were categorized according to sex, age, duration of hypertension history and educational level[10, 11]. Similarly, the basic physical information was assessed in terms of blood pressure (BP), heart rate (HR) and body mass index (BMI), and was completed by a registered nurse practitioner who was qualified and trained in accordance with international guidelines[10].

The outcome measures consisted of questionnaires; the primary included 14 items of PPHB $[3,15]$ and the secondary were 26 items of QOL (QOL: WHOQOL-BREF THAI) $[5,11]$ items on mindfulness[16], and 12 items on SE[3, 15]. All of them were evaluated in five frequency rating scales: 1 score (never or few), 2 score (sometimes), 3 score (usually), 4 score (often) and 5 scores (always), respectively, in assessing PPHB behaviors and feelings of perceived QOL, mindfulness and SE. They were all continuously rated for compliance in statistical analysis.

The steps to test the validity of the questionnaires were approved by five experts: a mindfulness trainer, a psychologist, two persons to assess the prevention and promotion behavior of hypertension, and a biostatistician, respectively. Then, the Cronbach's $\alpha$ was used to test 51 comparable representative samples. The result showed PPHB $(\alpha=0.833)$, QOL $(\alpha=0.910)$, mindfulness $(\alpha=0.710)$ and SE $(\alpha=0.843)$, respectively.

Figure 1.

Sample flow through the study and intervention process

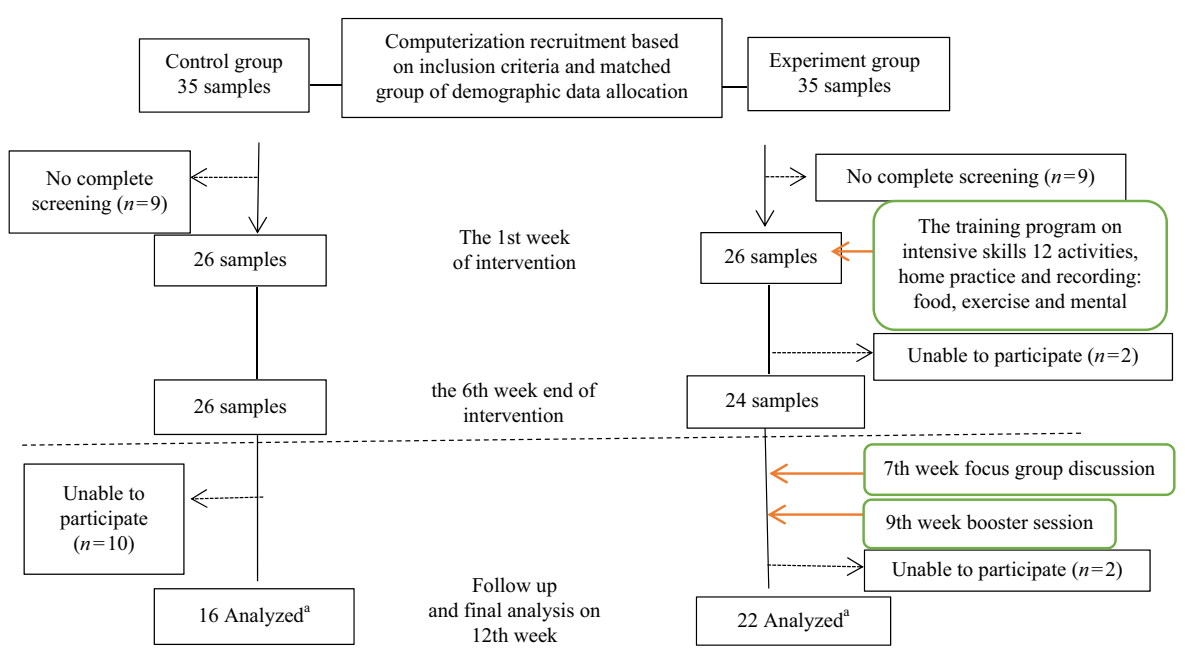




\section{Data collection}

\section{The mindfulness training program}

The protocol and informed consent were approved by the Research Ethics Committee of Thammasat University, MTU-EC-ES-2-218/59, with the approval date of January 18, 2017. All patients were presented with the research objectives and submitted their written informed consent before any study-related procedure was undertaken.

Instructor training: mindfulness training was obtained at Mahidol and Thammasat Universities for 10 days and at the Willpower Institute for 6 months. Meanwhile, a systematic review of principal strategies in mindfulness was summarized[8, 17]. The 12 MBHE skills-practice activities were trialed 15 times for retesting of reproducibility in comparable representative samples and were completed by following the advice of experts.

The instructor produced an intervention which comprised the principle of observing MBHE for the duration of $2 \mathrm{~h}$ per session that involved weekly group-meeting conversations. They were put into equal groups separated by morning and afternoon sessions. Six-week coherence practitioners observed and recognized feelings that had been adapted to everyday life as well as daily individual practice at home. They proceeded by making recordings throughout the follow-up phase on the 12th week.

Participants in the control group received health education and hypertension guidelines treatment[10] and were evaluated for questionnaire assessment on the 0th, 6th and 12th weeks. They received training after completion of the experiment group training (12th week).

Participants in the experiment group received health education and hypertension guidelines treatment[10]. In addition, the 12 activities skills practice in the six-week program were implemented by the addition of group conversation to create intention, attention and attitudes through careful listening, non-judgmentally accepting and respecting relationships. They were then evaluated by questionnaire assessment on the 0th, 6th and 12 th weeks. The MBHE practice program on intensive skills after six weeks of practising is shown in Table I.

\section{Statistical analysis}

We used SPSS version 22 for Windows to perform the $\chi^{2}$-test at the baseline of demographic data. The matched demographic and baseline interested variances data were tested by a $\chi^{2}$-test and an independent sample $t$-test. We then tested the difference score at the before (0th week), after (6th week) and follow-up (12th week) phases via the generalized linear model for repeated measurements in order to estimate effects. Then, by comparing and adjusting the means score, a standard error of $95 \%$ CI was found between the groups.

\section{Results \\ Characteristics of the participants}

The basic physical characteristics mean \pm SD in the control and experimental groups is as follows: SBP $131.8 \pm 12.5$ and $129.3 \pm 16.0 \mathrm{mmHg}$, DBP $83.7 \pm 7.6$ and $75.9 \pm 10.2 \mathrm{mmHg}$, HR $81.7 \pm 9.1$ and $88.2 \pm 12.7$ beats $/ \mathrm{min}$ and BMI $28.8 \pm 5.7$ and $26.9 \pm 2.8 \mathrm{~kg} / \mathrm{m}^{2}$. The demographic data showed no statistical significance between the experiment and control groups (Table II). The baseline in the total means score of the questionnaires showed no statistically significant differences (Table III).

\section{Changes in PPHB, QOL, perception in mindfulness and self-efficacy}

Post-intervention on the sixth week revealed that the experimental group had a statistically significantly higher total aspect of means score than the control group in PPHB 13.3, $p=0.001$, QOL 12.7, $p=0.001$, while the mindfulness and SE perception was at $4.7, p=0.001$ and 13.0, $p<0.001$, respectively. During the 12th week, during the follow-up phase, 
1st i. Breath of life exercise to raise awareness of the learning style of breathing and relaxation from breathing[18, 19]

ii. Knowing yourself and others - sit-in-others'-mind exercise to create mindfulness by group process, building intention, attention, and attitudes through careful listening, non-judgmentally acceptance and respecting relationships

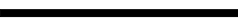

nnd

iii.

Food-loving exercise to raise self-awareness, acceptance an perceptions, low-sodium use; buying, adding seasonings, cooking low fa controlled dishes through the DASH diet and slow mastication[20, 21]

3rd iv-v. Body movement (or exercise), eight muscle relaxation groups and bodily strength exercise to create awareness and acceptance of observed physical symptoms[18, 19]

4th vi-viii. Physical and mental symptoms in words, magic box, wave of thought and feeling exercises to create awareness, consciousness and acceptance of the natural order (as well as physical and mental symptoms. In general)

5th ix-x. Spider-web wonders, and bottle-of-water exercises to build awareness and acceptance of mindfulness, and to foster observation of mental and physical symptoms. Quality of observation on the part of the observer and physical/mental phenomena as observed in daily life, similar to the metaphors "outside the cars" and Teflon-pan coating

Table I.
The MBHE practice program on intensive skill activities in six weeks
6 th

xi-xii.
Living robots alive and mental-bells exercises to raise consciousness, awareness, acceptance and self-regulation for observing the state of mind and behaviors in daily life

the experimental group had a statistically significant higher total aspect of means score than the control group in PPHB at 13.2, $p<0.001$, QOL at 11.2, $p<0.001$, and mindfulness and SE at $2.9, p=0.023$ and 13.7, $p<0.001$, respectively. (Table IV and Figure 2).

\section{Discussion}

First, the demographic data and prior questionnaires score data showed no statistically significant differences between the experiment and control groups and also suggested that the confounding factors were limited regarding mindfulness learning. Post-intervention and follow up at the 6th and 12th weeks in the experiment group showed that most of the aspects of PPHB and means scores in the experimental group were higher than in the control group. This difference can be explained by the MBHE integrated interpersonal group procession, which induced SE perceivability and mindfulness empowerment from the exercise phase that had been designed by Pender in 2011[3]. The relevant comparison of old and new experiences was defined in terms of their direct and indirect effects on awareness, acceptance and self-regulation in practising positive inner power through health

\begin{tabular}{lccc}
\hline & $\begin{array}{c}\text { Control } \\
n(\%)(n=26)\end{array}$ & $\begin{array}{c}\text { Experimental } \\
n(\%)(n=26)\end{array}$ & $p$-value \\
\hline $\begin{array}{l}\text { Gender } \\
\text { Male }\end{array}$ & $6(23.1)$ & & \\
Female & $20(76.9)$ & $5(19.2)$ & 0.734 \\
Age $(y r s)$ & & $21(80.8)$ & \\
Mean \pm SD & $52.5 \pm 5.2$ & $54.2 \pm 4.8$ & 0.239 \\
Educational level & & & \\
Primary level & $17(65.4)$ & $12(46.2)$ & 0.163 \\
Secondary and over level & $9(34.6)$ & $14(53.8)$ & \\
Duration of hypertension history (yrs) & $7.2 \pm 4.9$ & $5.9 \pm 4.0$ & 0.346
\end{tabular}

The demographic data of samples at baseline

Note: $p$-value from $\chi^{2}$-test for two groups and independent $t$-test for age and duration of hypertension 


\begin{tabular}{llcccc}
\hline Interest variable & Aspect & Total score & $\begin{array}{c}\text { Control means } \\
\pm \mathrm{SD}(n=26)\end{array}$ & $\begin{array}{c}\text { Experimental means } \\
\pm \mathrm{SD}(n=26)\end{array}$ & $\begin{array}{c}p \text {-value } \\
(2 \text {-tailed) }\end{array}$ \\
\hline PPHB & Total & 70 & $41.1 \pm 6.7$ & $44.3 \pm 5.9$ & 0.074 \\
& Food & 30 & $18.3 \pm 3.6$ & $19.4 \pm 4.0$ & 0.283 \\
& Exercise & 20 & $11.2 \pm 3.7$ & $11.7 \pm 2.2$ & 0.533 \\
& Mental & 20 & $11.6 \pm 2.4$ & $13.4 \pm 2.5$ & 0.014 \\
QOL & Total (item 1-26) & 130 & $92.0 \pm 10.9$ & $94.7 \pm 12.1$ & 0.397 \\
& Physical & 35 & $24.2 \pm 2.9$ & $25.7 \pm 3.7$ & 0.112 \\
& Mental & 30 & $23.1 \pm 3.4$ & $22.7 \pm 3.1$ & 0.675 \\
& Social relationship & 15 & $10.2 \pm 2.0$ & $10.6 \pm 2.0$ & 0.504 \\
MF & Environmental & 40 & $27.7 \pm 3.7$ & $28.8 \pm 4.7$ & 0.397 \\
& Total & 55 & $34.1 \pm 3.9$ & $33.8 \pm 4.8$ & 0.826 \\
& Awareness & 25 & $15.3 \pm 3.4$ & $15.4 \pm 3.5$ & 0.999 \\
& Acceptance & 15 & $8.5 \pm 2.9$ & $7.6 \pm 2.8$ & 0.275 \\
SE & Self-regulation & 15 & $10.3 \pm 3.0$ & $10.6 \pm 2.6$ & 0.660 \\
& Total & 60 & $35.5 \pm 5.7$ & $38.3 \pm 5.4$ & 0.073 \\
& Food & 25 & $15.4 \pm 3.7$ & $16.6 \pm 3.4$ & 0.235 \\
& Exercise & 20 & $11.0 \pm 4.0$ & $12.7 \pm 3.4$ & 0.107 \\
& Mental & 15 & $9.1 \pm 1.6$ & $9.4 \pm 2.6$ & 0.576
\end{tabular}

Notes: PPHB, prevention and promotion hypertension behaviors; QOL, quality of life; MF, mindfulness perceived; SE, self-efficacy perceived. $p$-value from independent simple $t$-test for two groups

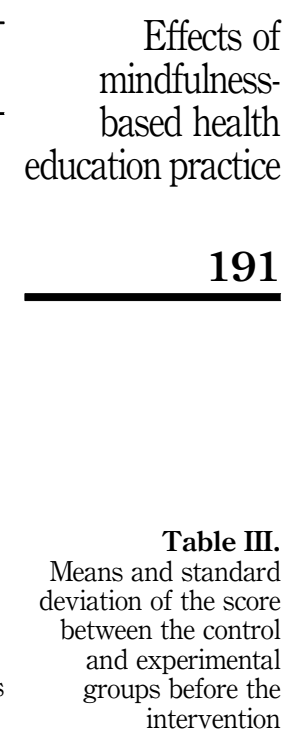

promotional behaviors. The mindfulness practice stimulated inspirational experiences through ocular (78 percent), aural (10 percent), nasal (5 percent), corporeal (5 percent), oral ( 2 percent) and sensory learning[12, 13]. Moreover, three domains in learning were developed in the cognitive, affective and psychomotor domains. In addition, the qualitative data from the focus group discussion were seen through a reduction of sodium and fat in cooking, reduction of flatulence through slow chewing due to mindful eating and reduction of exercise fatigue through mindful breathing. These data were also realized as a restoration of consciousness for problem solving in daily life through mental mindfulness. According to previous studies, it was demonstrated that the mindfulness practising group had mean scores that were higher than the control group in lifestyle and problem-focused coping strategies[22].

Second, the SE in PPHB perception directly motivated the expected behavioral promotion outcomes derived from knowledge and skills that had been gained through enactive mastery and vicarious experience perceptions[3, 4]. Skills involved included buying, reasoning and preparing food as well as slow mastication. Moreover, participants felt good from the positive effects of their daily exercise. By means of their self-reflection and open-minded group-procession, participants recognized their individual progression. Their performance regarding concentrated of intention, attention and attitude was increased due to self-management in a way that showed both cognitive and behavioral flexibility, while for others it revealed compassion[2, 23]. The mental relaxation in the SE mental activity of the mindful-breathing group process was positive in mind and body; a consistency of this result increased the mindfulness perception in terms of awareness, acceptance and self-regulation. Other studies have similarly demonstrated that practising mindful breathing meditation with other exercises can improve health promotional behavior in patients with hypertension and prehypertension[19, 24]. This result found that SE in PPHB during the exercise phase of the sixth week was not significant $(p<0.489)$, suggesting that this study may be addressing its focus on meditated movement rather than on the physical exercise. In addition, the goal of exercise in setting weight control brought the control body-weight lead to an increased level of perception at the 12 th week $(p=0.001)$. This study showed that the 
JHR

33,3

192

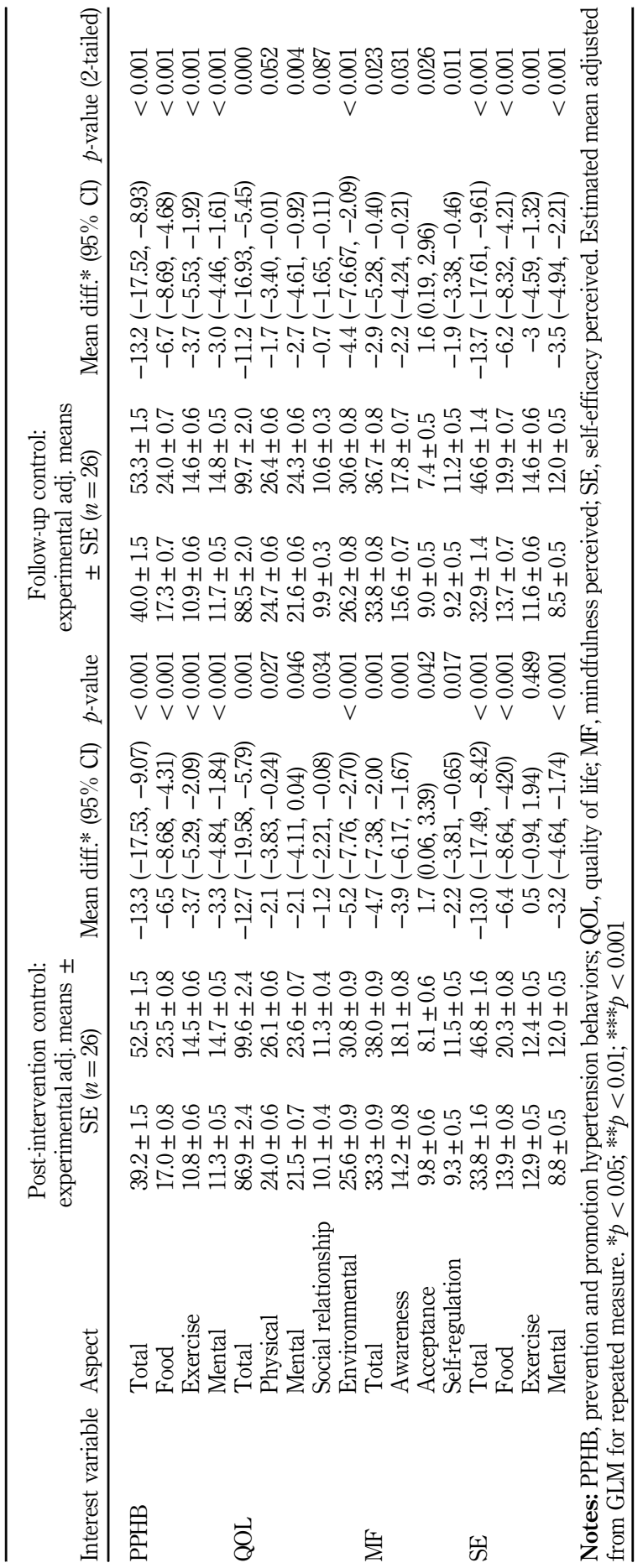

Table IV.

Means and standard error of the scores between the control and experimental group the post and follow up the intervention 


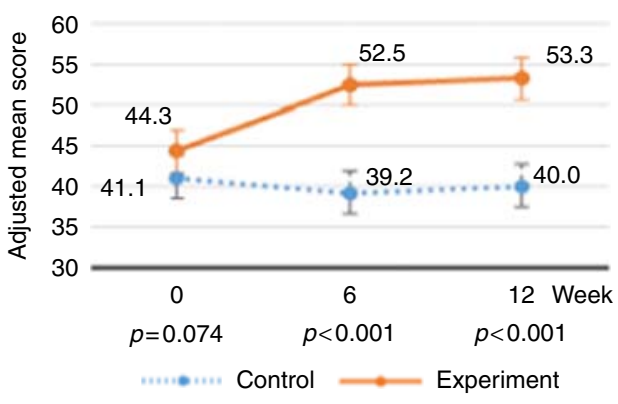

A. PPHB total

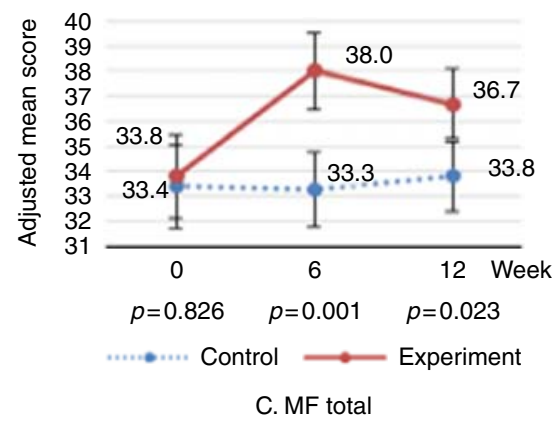

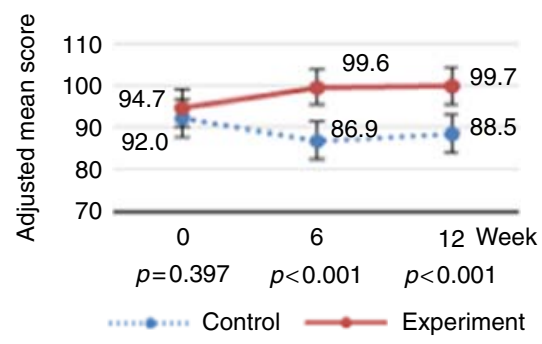

B. QOL total

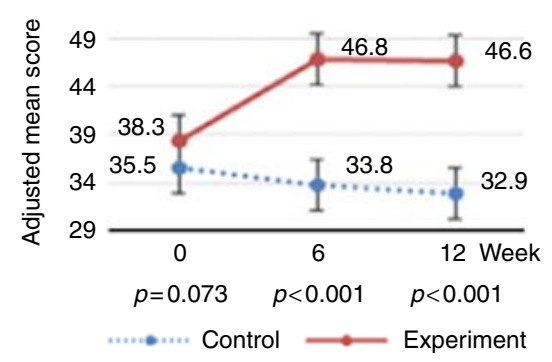

D. SE total

Notes: PPHB, prevention and promotion hypertension behaviors; QOL, quality of life; MF, mindfulness perceived; SE, self-efficacy perceived. Data are presented as means and self-efficacy for the experiment and control groups

principal of MBHE training with a natural body and mind symptoms approach had been created by individual intention, attention and attitude. The concept of self-reflection in a group conversation about mind and body symptoms also helped. This experience of everyday occurrences being incorporated into the program was positively experienced by the participants themselves[1, 2, 6].

Third, most of the total means score QOL at the sixth week increased statistically and significantly. However, for the physical and social relationships at the 12th week, the QOL aspect may have a gap of prolonged intervention apart from the interpersonal group, and only with supervision at the 9th week. These findings are contradictory to mindfulness training, which requires continuous experience[2,12]. Although the previous mindfulness training studies showed an improvement in psychological QOL and physiological QOL, there were no statistically significant differences in the physical aspects between the experiment and control groups[25]. The qualitative data from the focus group discussion were seen through reports of better sleep and no headache in most participants. In the holistic dimension of health as defined by the World Health Organization[5], the QOL focusing on daily life potential was as expected and was satisfied by economic conditions, society and the environment. The result of this study was consistent with other studies that showed that QOL improved with better sleep[26] and reduced headaches[27]. Furthermore, another effect of mindfulness study demonstrated that it improved the QOL for patients who were attending an out-patient clinic[28].

At the end of this study, on the 12th week, two participants discontinued their antihypertensive medication, and two participants received reduced doses of the 
JHR

33,3

194

antihypertensive drug as administered by their physicians. Previous studies demonstrated that the benefits from the research not only illustrated the value of mindfulness training, but also similar studies promoted health, and reduced chronic physical and mental illness among adults over 30 years of age[29]. Moreover, the results included a means of controlling biological issues such as acute or chronic pain and high $\mathrm{BP}$, conditions which responded successfully to non-pharmacological holistic treatment[29].

Finally, this study has several positive features. First, it initiated the match groups of demographic data and the means score that would be used to control the confounding factors at the baseline. However, after implementation in the experiment group, during the follow-up phase on the 12th week, ten participants in the control group were excluded (Figure 1). However, there was no active intervention in the control group. Thus, in the Table IV we controlled missing data using intention-to-treat analysis comparison and the data distribution was successfully tested by a normality plot before the use of statistical data. The adjusted means score, standard error and 95\% CI were compared between the groups. Moreover, this MBHE implementation integrated teach-back demonstrations that may result in better modifications than by more traditional methods [9, 17]. Participants who received MBHE experienced an increase in their awareness, acceptance and self-regulation, and ultimately achieved values and resilience in suffering from mental pain that was shown through compassion[2, 23]. Similar studies showed improvements in their mental and bodily well-being as they reached their goals of health promotion and QOL[30].

\section{Implications}

Based on the results of this study, the following recommendations can be made: first, patients should practice mindfulness and modifications in lifestyle practices that should be continued for intensive skills practice over a longer period in order to promote sustainability in behavior and in QOL. Second, mindfulness trainers should encourage the value of incorporating mindfulness practice at all times and through cooperation with their patients. Third, health practitioners should add MBHE as part of a patient's routine for recovery. Fourth, educational institutions should incorporate mindfulness into the educational programs of all students.

\section{Conclusions}

The MBHE should be applied as a complementary treatment in stage I hypertension amongst patients in groups to produce awareness, acceptance and self-regulation for self-management in cognitive and also to control behavior promotion. These actions would have a positive effect on patients suffering from hypertension and at risk of developing cardiovascular problems.

\section{Acknowledgments}

The authors would like to express their sincere appreciation to all residents and staff of the Primary Care Units involved in this research. The authors acknowledge the kind assistance of Associate Professor Dr Chatchawan Silpakit and Assistant Professor Lampu Kosulwit, MD, Professor Peera Burankitjaroen, MD, Associate Professor Sutreera Phatrayuthawan $\mathrm{PhD}$ and Assistant Professor Somkiat Sangwatanaroj, MD for validating the instrument. The authors would also like to thank participants at the primary care units. This study was sponsored by a grant from Thammasat University and National Science and Technology Development Agency, NSTDA Thailand.

Conflict of interest: the authors declare no conflict of interest with respect to this study. 


\section{References}

1. Kabat-Zinn J. Mindfulness-based interventions in context: past, present, and future. Clin Psy-chol Sci Prac. 2003; 10(2): 144-56.

2. Shapiro SL, Carlson LE, Astin JA, Freedman B. Mechanisms of mindfulness. J Clin Psychol. 2006; 62(3): 373-86.

3. Pender NJ, Murdaugh CL, Parsons MA. Health promotion in nursing practice. Boston, MA: Pearson; 2011.

4. Bandura A. Social foundations of thought and action: a social cognitive theory. Englewood Cliffs, NJ: Prentice-Hall; 1986.

5. The World Health Organization Quality of Life assessment [WHOQOL]. Position paper from the World Health Organization. Soc Sci Med. 1995 Nov; 41(10): 1403-9.

6. Abbott RA, Whear R, Rodgers LR, Bethel A, Coon JT, Kuyken W, et al. Effectiveness of mindfulness-based stress reduction and mindfulness-based cognitive therapy in Vascular disease: a systematic review and meta-analysis of randomised controlled trials. J Psychosom Res. 2014; 76(5): 341-51.

7. Centers for Disease Control and Prevention [CDC]. National center for chronic disease prevention and health promotion, division for heart disease and stroke prevention. A public health action plan to prevent heart disease and stroke fact sheet; 2016 [updated: 2016 June 1; cited 2018 May 26]. Available from: www.cdc.gov/dhdsp/data_statistics/fact_sheets/fs_bloodpressure.htm

8. Sangprasert P, Palangrit S, Buranatrevedh S, Tiyoa N, Pattaraarchachai J. A systematic review of the effectiveness of mindfulness meditation and contemplation upon vascular disease patients. TMJ. 2018; 18(1): 79-92.

9. Cx V. Mindfulness in health education and health promotion: in handbook of research o adult and community health education: tools, trends and methodologies. Florida: Florida Atlantic University; 2014.

10. Mancia G, Fagard R, Narkiewicz K, Redon J, Zanchetti A, Bohm M, et al. 2013 ESH/ESC guidelines for the management of arterial hypertension: the Task Force for the management of arterial hypertension of the European Society of Hypertension (ESH) and of the European Society of Cardiology (ESCJ). Hypertens. 2013 Jul; 31(7): 1281-357. doi: 10.1097/01.hjh.0000431740.32696.cc

11. Nyklicek I, Dijksman SC, Lenders PJ, Fonteijn WA, Koolen JJ. A brief mindfulness-based intervention for increase in emotional well-being and quality of life in Percutaneous Coronary Intervention (PCI) patients: the mindful heart randomized controlled trial. J Behv Med. 2014; 37(1): 135-44.

12. Seddon GM. The properties of Bloom's taxonomy of educational objectives for the cognitive domain. Review of Educational Research. 1978; 48(2): 303-23.

13. Dale E. Audiovisual methods in teaching. 3rd ed. New York, NY: Dryden Press nd Holt, Rinehart \& Winston; 1969.

14. Faul F, Erdfelder E, Lang AG, Buchner A. G*Power 3: a flexible statistical power analysis program for the social, behavioural, and biomedical sciences. Behav Res Methods. 2007; 39(2): 175-91.

15. Sangprasert P, Buranatrevedh S, Pipatsatitpong D. The effectiveness of hypertensive management programs and social support in primary health care systems: preliminary study. Siriraj Med J. 2016; 68(6): 369-76.

16. Silpakit O, Silpakit C. A Thai version of mindfulness questionnaire: Srithanya Sati scale. East Asia Arch Psychiatry. 2014; 24(1):23-9.

17. Ha Dinh TT, Bonner A, Clark R, Ramsbotham J, Hines S. The effectiveness of the teach-back method on adherence and self-management in health education for people with chronic disease: a systematic review. JBI Database System Rev Implement Rep. 2016 Jan; 14(1): 210-47. doi: 10.11124/jbisrir-2016-2296

18. Zou Y, Zhao X, Hou YY, Liu T, Wu Q, Huang YH, et al. Meta-analysis of effects of voluntary slow breathing exercises for control of heart rate and blood pressure in patients with cardiovascular diseases. Am J Cardiol. 2017 Jul 1; 120(1): 148-53. doi: 10.1016/j.amjcard.2017.03.247. Epub 2017 Apr 12. 
JHR

33,3

196

19. Hughes JW, Fresco DM, Myerscough R, Dulmen VM, Carlson LE, Josephson R. Randomized controlled trial of mindfulness-based stress reduction for prehypertension. Psychosom Med. 2013 Oct; 75(8): 721-8. doi: 10.1097/PSY.0b013e3182a3e4e5

20. Cuddy ML. Treatment of hypertension: guidelines from JNC 7 (the seventh report of the joint national committee on prevention, detection, evaluation, and treatment of high blood pressure 1). J Pract Nurs. 2005; 55(4): 17-21, 22-3.

21. Sacks FM, Svetkey LP, Vollmer WM, Appel LJ, Bray GA, Harsha D, et al. Effects on blood pressure of reduced dietary sodium and the dietary approaches to stop hypertension (DASH) diet. DASHsodium collaborative research group. N Engl J Med. 2001 Jan 4; 344(1): 3-10.

22. Nejati S, Zahiroddin A, Afrookhteh G, Rahmani S, Hoveida S. Effect of group mindfulness-based stress-reduction program and conscious yoga on lifestyle, coping strategies, and systolic and diastolic blood pressures in patients with hypertension. J Tehran Heart Cent. 2015 Jul 3; 10(3): 140-8.

23. Siegel RD, Germer CK, Olendzki A. Mindfulness: what is it? Where did it come from? New York, NY: Springer; 2009.

24. Blom K, Baker B, How M, Dai M, Irvine J, Abbey S, et al. Hypertension analysis of stress reduction using mindfulness meditation and yoga: results from the HARMONY randomized controlled trial. Am J Hypertens. 2014 Jan; 27(1): 122-9. doi: 10.1093/ajh/hpt134. Epub 2013 Sep 14.

25. Son JV, Nyklíček I, Pop VJ, Blonk MC, Erdtsieck RJ, Spooren PF, et al. The effects of a mindfulnessbased intervention on emotional distress, quality of life, and $\mathrm{HbA}(1 \mathrm{c})$ in outpatients with diabetes (DiaMind): a randomized controlled trial. Diabetes Care. 2013 Apr; 36(4): 823-30. doi: 10.2337/dc 12-1477. Epub 2012 Nov 27.

26. Black DS, O'Reilly GA, Olmstead R, Breen EC, Irwin MR. Mindfulness meditation and improvement in sleep quality and daytime impairment among older adults with sleep disturbances: a randomized clinical trial. JAMA Intern Med. 2015 Apr; 175(4): 494-501. doi: 10.1001/jamainternmed.2014.8081

27. Bakhshani NM, Amirani A, Amirifard H, Shahrakipoor M. The effectiveness of mindfulness-based stress reduction on perceived pain intensity and quality of life in patients with chronic headache. Glob J Health Sci. 2015 Aug 6; 8(4): 142-51. doi: 10.5539/gjhs.v8n4p142

28. Gimpel C, Scheidt CV, Jose G, Sonntag U, Stefano GB, Michalsen A, et al. Changes and interactions of flourishing, mindfulness, sense of coherence, and quality of life in patients of a mind-body medicine outpatient clinic. Forsch Komplementmed. 2014; 21(3): 154-62. doi: 10.1159/0003 63784. Epub 2014 Jun 18.

29. Williams H, Simmons LA, Tanabe P. Mindfulness-based stress reduction in advanced nursing practice: a nonpharmacologic approach to health promotion, chronic disease management, and symptom control. J Holist Nurs. 2015 Sep; 33(3): 247-59. doi: 10.1177/0898010115569349. Epub 2015 Feb 11.

30. Fernros L, Furhoff AK, Wandell PE. Improving quality of life using compound mind-body therapies: evaluation of a course intervention with body movement and breath therapy, guided imagery, chakra experiencing and mindfulness meditation. Qual Life Res. 2008 Apr; 17(3): 367-76. doi: 10.1007/s11136-008-9321-x. Epub 2008 Mar 7.

\section{Corresponding author}

Pantip Sangprasert can be contacted at: pantips162@gmail.com

For instructions on how to order reprints of this article, please visit our website:

www.emeraldgrouppublishing.com/licensing/reprints.htm

Or contact us for further details: permissions@emeraldinsight.com 